\title{
Pierre Boulez e a análise musical: Notations
}

\author{
Carole Gubernikoff* \\ Universidade Federal do Estado do Rio de Jameiro
}

\section{Resumo:}

A análise musical de obras de Pierre Boulez exige um posicionamento diante da quantidade de informações existentes em textos do próprio autor, em entrevistas e em comentaristas. Dentre estas informações, selecionamos apresentar a experiência de Jonathan Goldmann frente à análise de obras de Pierre Boulez. Algumas das principais características de estilo encontradas em suas obras, nos aspectos de textura, ritmo e proliferação podem ser verificadas em Douze Notations para piano e nas Notations, para orquestra.

Palavras-chave: Pierre Boulez; análise musical; Jonathan Goldmann; Douze Notations para piano e Notations, para orquestra

* Carole Gubernikoff é professora de análise musical na UNIRIO e pesquisadora em técnicas e estéticas da música contemporânea. Formada em composição na USP, foi aluna de Willy Correa de Oliveira. Fez mestrado e doutorado na Escola de Comunicação da UFRJ. Para sua tese de doutorado, Música e representação: das durações aos tempos, recebeu bolsa especial de doutorado do CNPq, no IRCAM, em Paris. Foi bolsista de pós-doutorado por um ano na Columbia University, em Nova York, em 1998. Em 2008, fez estágio pósdoutoral na École Normale Sup. com o compositor e musicólogo François Nicolas. Atualmente desenvolve pesquisa apoiada pelo CNPq sobre Pierre Boulez e o pensamento musical da segunda metade do século XX. 


\section{Frente às obras e textos de Pierre Boulez}

Para a análise de obras de Pierre Boulez, nos debruçamos sobre a escuta das obras e a leitura das partituras e recorremos aos textos do autor e de seus comentaristas para nos guiar no que à primeira vista nos parecia um emaranhado de informações. A escuta das obras e a leitura das partituras não deixaram a menor sombra de dúvida que o pensamento musical propriamente dito se encontrava nas obras. Os textos podem apoiar ou apontar direções para uma aprendizagem musical a partir da leitura das partituras, mas raramente esclarecem o suficiente para servirem de orientação. No caso, o guia para nossas propostas de análise de obras de Pierre Boulez é a escuta.

A atividade de análise musical é tema controverso na obra de Boulez, e a este respeito o musicólogo canadense, Jonathan Goldmann, autor de uma tese sobre Anthèmes, faz observações importantes não apenas sobre sua experiência na análise de obras de Pierre Boulez, que foi baseada principalmente nas indicações do próprio compositor a respeito da análise musical. Outras informações importantes podem ser extraídas de um artigo que comenta os limites entre o que a análise ajuda a esclarecer e a ouvir e aquilo que, na análise, corresponde mais à procura de um ego próprio naquilo que é observado, como parece ser o caso, muitas vezes, das análises do próprio Boulez.

Logo no início, o texto de Goldmann recupera a lembrança de como, no inicio de sua carreira, Boulez se referia às análises de música dodecafônica então vigentes (principalmente se referindo a René Lleibowitz), chamando-as de "tabelas de símbolos enganadores", "lista de horários de trens sem trens e sem destinações". Em seu livro A Música Hoje (Penser la musique aujourd'hui), publicado na França em 1963, Boulez se refere a este tipo de análise da seguinte maneira: “Na melhor das hipóteses, encontramo-nos diante de 'cálculo' dos acontecimentos musicais: ora, cálculo e pensamento não se deixam reduzir a uma mesma operação." (2007, p. 15). 
O próprio Boulez realizou em seus cursos, em Darmstdat, análises de obras de Webern sob vários ângulos: no vertical, os acordes resultantes das séries; no horizontal, o encaixe e a sobreposição de notas das séries. Ainda em Penser la Musique Aujourd'hui apresenta vários esboços de diferentes possibilidades de construções seriais, especialmente em obras de Alban Berg e Anton Webern.

Uma das análises mais importantes realizadas por Boulez que se encontra em Relevés d'Apprenti, também de 1963, é a da Sagração da Primavera de Stravinsky, onde retoma os "personagens rítmicos" de Messiaen e elabora verdadeiras tabelas dedutivas a partir do que ele considera os ritmos básicos de toda a obra, que estariam nos primeiros cinco compassos da "Introdução". Apesar de demonstrar estas premissas claramente em sua análise da Sagração, os desdobramentos desta proposta são mais esclarecedores da aplicação destes métodos dedutivos na obra do próprio Boulez que na obra de Stravinsky. As conseqüências, nas obras de Boulez, são visíveis, por exemplo, em obras como Éclat, em que a base rítmica é construída na sobreposição e justaposição de grupos de quantidades crescentes e decrescentes. Em Notations, para orquestra, principalmente a número 2, a ligação com a escrita rítmica e textural da Sagração da Primavera de Stravinsky é evidente. A complexidade harmônica, entretanto, é de natureza diferente, apesar de também preservar certo nível de diatonismo. A sobreposição de camadas rítmicas em texturas complexas, os grupos quialtéricos e as sonoridades em frulatos e trêmolos são uma constante na obra de Boulez.

Seguindo com o artigo de Goldmann, ele conclui apresentando as três acepções de análise musical que podem ser extraídas dos textos de Boulez. 1 uma análise no estilo Boulez, em que se extraem conseqüências labirínticas e dedutivas de um material inicial, como as notas iniciais ou um acorde; 2 uma análise "falsa", que mutila seu objeto, feita na intenção de recolher materiais para quem analisa; 3 - a presença de traços "didáticos" encontráveis em algumas obras de Boulez, sinais que apontam para algumas trilhas que podem ser seguidas por quem escuta e por quem analisa. Um dos exemplos selecionados por Goldmann é o da partitura de Marteau sans Maitre, na qual são encontrados pequenos sinais de cesura que indicam a segmentação harmônica. 


\section{A proposta de análise de obras de Pierre Boulez e a reescrita de Douze Notations pour piano}

A posição da pesquisa que se encontra em desenvolvimento é aquela que tem se mantido desde o início de nossas atividades: buscar através da análise uma aprendizagem sobre a música e não uma aplicação de uma metodologia "sem objeto". Neste sentido, nunca foi adotada uma aplicação de uma metodologia a um objeto. Ao contrário, a aprendizagem da música terá de ser feita em termos da própria obra e não apenas a partir de fatores externos que não deixam de ser extremamente valiosos, principalmente quando os sinais vêm do compositor da obra. Alguns dos textos de Boulez foram escritos concomitantemente à composição de determinadas obras e muitas vezes se referem a elas de maneira indireta, sem mencionar o título e a época. Cabe aos pesquisadores encontrar estas possíveis relações e estabelecer elos que apóiem seu exercício, mas não se apoiar única e exclusivamente nestes textos, com o perigo de ver suas análises e conclusões desmentidas pelos textos musicais.

É comum encontrarmos nas obras de Pierre Boulez obras que são reescritas várias vezes, e que se desdobram em novas obras. Esta característica de permanente mutação e de novas possibilidades é um dos traços que foram preservados ao longo de sua extensa carreira de compositor.

No caso de Notations, a história é fundadora da trajetória de Pierre Boulez. Esta foi sua primeira obra, composta para a classe de composição de Olivier Messiaen, onde experimentou a técnica dodecafônica de composição em sua versão mais "original”. São 12 pequenas peças para piano, cada uma com doze compassos de duração, iniciadas pela nota de seqüência da série. A primeira peça começa com a nota 1 , a segunda com a nota 2 e assim sucessivamente. Logo, a configuração da seqüência das notas, apesar de inalterada, é considerada na perspectiva da permutação - que é uma das características da obra do próprio Messiaen que, na época, estava compondo Modos de Valor e Intensidade, em que são controlados e permutados, além das notas, as intensidades e as durações. A obra inaugura o que passou a se chamar de Serialismo Integral, técnica que 
será desenvolvida de maneiras diferentes por cada um dos compositores seriais e alunos de Messiaen, na década de 50, sendo que os dois mais importantes, Boulez e Stockhausen seguiram trilhas totalmente diferentes (vide Gubernikoff, 1993).

Boulez desenvolverá uma técnica dedutiva, que consiste em extrair de uma série de notas, a partir de uma série, valores quantitativos abstratos que servirão para estabelecer correspondências em cada um dos parâmetros que serão transformados numa seqüência de eventos musicais, como gestos, figuras rítmicas, harmonia e instrumentação. Desta seqüência, são deduzidos os motivos principais. O controle das intensidades, apesar de ter sido experimentado, redundou em absoluto fracasso. Em Douze Notations para piano, Boulez ainda está experimentando com a série de 12 notas da escala cromática. Várias novidades, no entanto, são introduzidas em sua manipulação, como a prática da multiplicação para criar novos campos harmônicos, a concentração em determinados intervalos que dão uma sonoridade específica para determinados gestos e a utilização não linear da série em vários momentos.

Estas pequenas peças foram consideradas inúteis ou perdidas durante mais de 30 anos. Boulez negava sua existência ou dizia que haviam se extraviado! No final da década de 70 , quando ele já havia desenvolvido e dominado seu estilo completamente, volta a elas como material para obras orquestrais extraordinárias - compondo aos poucos e sem uma ordem pré-determinada - as Notations, para orquestra. As quatro primeiras, Notations I, II, III e IV foram compostas em 1978; a Notations VII, para orquestra, em 1998. Notations VIII será provavelmente a próxima, uma vez que Boulez teria se comprometido a estreá-la com a Orquestra Filarmônica de Chicago.

O primeiro impacto ao ouvir a versão orquestral se refere às dimensões que transformam pequenas peças para piano em obras para grande orquestra, com instrumentação riquíssima e muita percussão. Outra notável transformação é a duração de cada peça, ficam mais longas; e o perfil da escuta original se perde totalmente na profusão instrumental através dos processos de multiplicação e proliferação que são comuns nas obras de Pierre Boulez. 
Encontramos nelas o foco das idéias composicionais de Boulez: exuberância instrumental e sonora aliadas a rigor composicional extraído de pequenos elementos que se proliferam, formando camadas texturais e multiplicidade de eventos em que as percussões exercem uma função importante e colaboram para a sonoridade global da obra.

Observando a partitura orquestral, um dos aspectos mais importantes é a diferença de tratamento rítmico e métrico. Cada uma das Douze Notations para piano tem 12 compassos livres, sem determinação de unidade de compasso. Em cada uma, o caráter (geralmente indicado no local da indicação do andamento), o gesto e seu ritmo resultante delimitam as configurações. Nas Notations, para orquestra, os compassos são claramente definidos, havendo maior economia na variedade de gestos e maior exploração da densidade e das texturas. Os ritmos se tornam mais claros através da repetição de fórmulas e de células que, no original para piano, aparecem apenas uma vez, e na versão orquestral, se transformam em modelos produtores de "patterns". Nas Notations para piano podemos auferir uma seção para cada gesto. Já nas Notations, para orquestra, as seções podem ser constituídas de vários gestos que participam de uma textura global. A presença e a repetição variada de cada um compõem as texturas e os planos sonoros.

A orquestração se caracteriza pela subdivisão e multiplicação das camadas, sendo que todas as seções instrumentais apresentam divisões. Nas cordas, as divisões são por estantes, com cada instrumento realizando uma voz completa no sentido do contraponto, o que resulta em grande complexidade textural. Temos assim, nestas peças, algumas das características do pensamento musical de Boulez: a exuberância orquestral, certamente herdada de sua experiência de análise e interpretação das obras de Stravinsky; a harmonia dedutiva com grupos harmônicos permutáveis e notas-pólo; a textura instrumental contrapontística; o ritmo resultante pela multiplicação de gestos.

A harmonia é um dos pontos fundamentais da análise das obras de Boulez. Em seu livro Pierre Boulez, a world of harmony (1990), Lev Kobliakov decifra uma das partituras mais complexas e mais exuberantes da obra de Boulez, - Marteau Sans Maître. Nesta obra foi aplicado o serialismo integral num 
processo de composição em que todos os parâmetros do som são submetidos a uma lógica de ordenação em séries. Quanto às séries das harmonias, Boulez propõe uma modificação profunda em relação ao dodecafonismo, tal como havia sido praticado por Schoenberg e deduzido a partir de Anton Webern. As séries de Boulez não têm necessariamente doze sons. Podem ter o número de sons que sua proposta inicial considerar suficiente, os campos harmônicos ou os domínios sonoros (domaines). A partir desta série inicial, eles são agrupados em acordes de 1, 2, 3 ou 4 sons. Estes grupos são considerados os acordes, que constituirão o material harmônico. A seqüência das notas de cada grupo pode ser permutada e a seqüência dos acordes também. Assim, ao invés da seqüência imutável de notas da série dodecafônica, Boulez, desde os anos cinqüenta, se preocupa com uma harmonia em que a permutação de elementos exerce uma importância muito grande no resultado sonoro. Este processo, chamado de dedutivo, em que um material original produz deduções inesperadas, produz um efeito de superfície complexo em relação à estruturação original. Estes procedimentos podem ser considerados generativos, uma vez que elementos originais primários dão origem a uma grande complexidade de superfície. A estes procedimentos são acrescentadas as notas-pólo, em torno das quais podem ser criadas áureas, que são notas ornamentais. O mesmo tipo de procedimento pode ser empregado para os acordes, que serão descritos, ou seja, linearizados e transformados em novas notas-pólo.

Na composição das Notations, para orquestra, há uma ligação entre o gesto instrumental e a harmonia. As Notations para piano são dodecafônicas (mesmo que em algumas o tratamento do dodecafonismo não seja absolutamente ortodoxo), mas suas preocupações estéticas e as técnicas composicionais empregadas, como a utilização de gestos expressivos, a ocupação do espaço sonoro e a criação de núcleos harmônicos ostinatos são absolutamente originais em relação às práticas dodecafônicas da época e têm finalidade expressiva.

Por ocasião das comemorações dos 80 anos de idade de Boulez, seus escritos foram reeditados e reagrupados em novas organizações. Na introdução 
ao volume Leçons de Musique, que corresponde ao livro Points de Repère 3 (2005), os textos escritos na época da composição de Notations, para orquestra, foram identificados. Em um destes textos, "O Olho e a Orelha", Boulez nomeia os dois procedimentos que consideramos importantes para o entendimento das recomposições: "liberdade de descrição" e "aura". Na "liberdade de descrição" escolhe-se um objeto sonoro harmônico vertical que será "descrito" horizontalmente, se desdobrando em texto contínuo (podemos reconhecer aí um dos procedimentos descritos por Kobliakov, em Marteau san Maitre). A partir deste objeto, Boulez seleciona notas-pólo - que terão durações mais longas - que serão "descritas" através de curvas, gestos e modelos rítmicos. A "aura" consiste na interpolação de pequenas notas, comparáveis a appogiature e accacciature, que serão incluídas nos objetos na forma de notas suplementares que alterarão a extensão da figura. Estes procedimentos podem ocorrer em relação aos valores longos também, o que produz uma variação permanente, uma extensão formal que liberta a escrita das formas convencionais.

Eu retomo a analogia de um universo em expansão, mas se poderia falar de uma forma infinita [...] que não cessa de se transformar e que não tem necessidade dos esquemas antigos para existir. (2005, p. 419).

Partindo desta hipótese, observamos alguns procedimentos comuns às Notations, para orquestra. Nelas, as peças para piano estão contidas de duas maneiras. Como texto presente na transcrição literal de cada enunciado das peças para piano, imersa na instrumentação global; como fator local de proliferações, como presença ausente transformando-se em material composicional generativo que dará origem às seções e aos gestos de toda a peça

Este artigo trata apenas da ponta de um Iceberg, pois o universo estético composicional de Pierre Boulez parece inesgotável e com proliferações que nos remetem a um infinito de possibilidades. Entretanto, a escuta e a decifração da singularidade de cada peça pode revelar certos mecanismos e repetições, pequenos sinais (pontos de referência, pegadas) que podem nos conduzir através da decifração dos enigmas. 


\section{Referências}

BOULEZ, P. A música hoje. 3. ed. São Paulo: Perspectiva, 2007.

. L'oeil et l'oreille. In: Leçons de musique, points de repére 3. Paris: Chr. Bourgois, 2005.

. Notation VII pour orchestra. Wien: Universal, 1998.

. Stocktakings from an Apprenticeship. Oxford: Oxford Univ. Press, 1991.

. Douze Notations pour piano. Wien: Universal, 1986.

. Notations I - IV pour orchestra. London: Universal, 1978. 4 v.

GUBERNIKOFF, C. Boulez, compositor pensivo. In: Anais do XVII Congresso da ANPPOM. São Paulo: UNESP, 2007.

. Boulez: Improvisação I sobre Mallarmé. Opus, Rio de Janeiro, v. 4, 1995.

. Música e representação, das durações aos tempos. Tese de doutorado - UFRJ, Rio de Janeiro, 1993.

KOBLIAKOV, L. Pierre Boulez, a world of harmony. [s.I.]: Routledge, 1990.

GOLDMANN, J. Analyse de, par, et selon Pierre Boulez: un parcours à travers les écrits et les oeuvres. In: Actes du Colloque international: Composer au XXle Siècle Processus et Philosophies. Montréal, Canada, 2007.

Carole Gubernikoff: gubernik@terra.com.br

Recebido e aprovado em 02 de outubro de 2008 